\title{
THE SIGNIFICANCE OF THE DIRECTION OF THE P WAVE IN DEXTROCARDIA AND ISOLATED LEVOCARDIA
}

\author{
BY \\ MAURICE CAMPBELL AND GEOFFREY REYṄOLDS
}

From the Cardiac Department, Guy's Hospital

Received May 19, 1952

The electrocardiogram of dextrocardia with situs inversus is well known and is often quoted as one of the rare examples where a diagnosis can be made on the electrocardiogram alone. Taussig (1947), Wood (1950), Brown (1950), and White (1951) all accept this orthodox view, though Brown adds that the $P$ wave may sometimes be upright in lead I: he quotes the case of Beaujeu and Bège (1937) who said that their case was the second example they had seen of a positive PI in dextrocardia with complete situs inversus. It is generally taught that except for the association with bronchiectasis and sinusitis, there is no disadvantage in having dextrocardia with situs inversus and that the heart is normal in every other way being a mirror image of the normal.

Wood (1950) says that mirror-image dextrocardia is almost invariably associated with complete transposition of the viscera. White (1951) says that in mirror-image dextrocardia, whether the abdominal viscera are transposed or not, lead I of the electrocardiogram is completely inverted. Without full investigation one does not as a rule know if a heart on the right is a mirror image or not, and the general problem is, therefore, better stated in simpler terms.

If the heart and the abdominal viscera are all transposed and the patient is acyanotic, generally the heart is normal and is, in fact, a mirror image of the normal. But at any large clinic for congenital heart disease there are several with other congenital malformations added to the dextrocardia and transposition of the viscera. Taussig (1947) says that her experience includes many such cases in which the other congenital malformations have produced cyanosis; and with this we are in complete agreement. Here, presumably, the heart is not a mirror image of the normal or additional defects are added to a mirror-image dextrocardia, for the presence of complete situs inversus cannot prevent a patient having Fallot's tetralogy any more than a normally placed heart can: indeed, it may make it more likely.

Isolated Dextrocardia. When, on the other hand, the heart is on the right without transposition of the abdominal viscera (isolated dextrocardia) there are generally other congenital malformations of the heart. Röesler (1930) maintained that this was always so, and Lichtman (1931) among 161 reported cases found only three in which there was no associated congenital malformation. Here again, the heart is presumably not a mirror image of the normal, but as suggested by White (1951) there may be some cases where the heart is a mirror image and the electrocardiogram may then show the classical picture of dextrocardia with situs inversus.

There is much less general agreement about the electrocardiogram of isolated dextrocardia. Brown divides these cases into two groups: in the first, cavities are inverted and " the electrocardiogram may or may not show the alterations characteristic of dextrocardia of the mirror-image type: the uncomplicated type presents the classical picture." In his second group the heart cavities are not inverted (dextroversio cordis), and "in cases where an electrocardiogram has been done there was no change in lead I."

Several authors in reporting single cases of isolated dextrocardia have noted the $P$ wave is not inverted in all these cases. For example, Ruskin et al. (1943) reported a case of isolated 481 
dextrocardia, a woman, aged 55, who had borne seven children. The T wave was inverted in leads I and II but the P wave was not, and they thought the electrocardiogram was typical of isolated dextrocardia. Angiocardiograms showed that there was a left-sided superior vena cava which entered the venous atrium on the right.

Isolated Lavocardia. Still less has been written about the electrocardiogram of lævocardia with transposition of the abdominal viscera. Some authors in reporting single cases of this type have noted that the P wave in lead I was inverted in some but not in all cases, although the heart was on the left.

Forgacs (1947) reported two cases: in one where an electrocardiogram was available PI was upright but PII and PIII were fairly sharply inverted. Thomson (1950) reported two cases: in one PI was upright, PII biphasic, and PIII inverted, but in the other the picture was " highly suggestive of a true dextrocardia," PI being deeply inverted and PIII upright. He said that he had found very few electrocardiographic records of this syndrome and that those published showed no uniform pattern. He referred to the case of Grieshaber (1936) and to a more doubtful one of Shaw and Blake (1924) as showing "inverted electrocardiograms": but we think the latter is really a case of dextrocardia with the heart rather centrally placed.

Donzelot et al. (1949-50) also reported two cases. In both the P wave was upright in lead I, though in one it was inverted in leads II and III: in both the venous atrium was in its normal position on the right. Each had a ventricular septal defect with an over-riding aorta and one had severe pulmonary stenosis.

Young and Griswold (1951) in a valuable paper have reported their findings in 8 cases of isolated lævocardia but do not mention the direction of the $P$ wave in this group of cases.

It is clear from these statements that there is general agreement about the inversion of $P$ and the other waves in lead I in dextrocardia with complete situs inversus, but much less agreement about the usual electrocardiographic pattern of isolated dextrocardia without transposition of the abdominal viscera or of isolated lævocardia with transposition of the abdominal viscera. The large number of patients with congenital heart disease whom we have seen in the last few years (1947-51) have given us a chance to examine these questions more thoroughly. Among 670 cyanotic patients there were 31 with dextrocardia (usually isolated) or isolated lævocardia, and among 454 acyanotic patients there were 5 with dextrocardia or isolated lævocardia. We have added 4 others seen since, making 40 cases in all.

\section{FINDINGS IN OUR 40 CASES}

Changes of pacemaker with differently shaped $P$ waves and different $P-R$ intervals are common in congenital heart disease and these cases are no exception. These give rise to no difficulty if it is clear which is the normal sinus rhythm. As will be seen from the notes to Tables I and II, however, this is not always clear and there were cases where from time to time the $P$ wave had a different form and direction. When there was any doubt we have taken the form that seemed most usual and have added a footnote about the changes.

Dextrocardia with Transposed Visera. There were 11 such cases. Other congenital malformations of the heart were absent in 2 patients in whom the dextrocardia was a chance finding, but were present in the other 9 of whom 2 were acyanotic and 7 were cyanotic. Two at least of these last had some lesion similar to Fallot's tetralogy as they benefitted greatly by a subclavianpulmonary anastomosis. None of these 11 patients have died.

As would be expected, PI was inverted in 9 of these 11 with complete situs inversus, but in 2 PI was upright (Cases $\mathrm{O} 347$ and P086). One of the latter was investigated by angiocardiography and was certainly not a mirror-image dextrocardia, the right superior vena cava and atrium being almost in the position that is normal when the heart is on the left.

Isolated Dextrocardia. There were 15 cases with the heart on the right but with the abdominal viscera normally placed. All had other congenital malformations of the heart, 13 being cyanotic and 2 acyanotic. 
Three have died. Of these, one (Case P165) had a single atrium, a single A-V valve, two ventricles, and transposition of the aorta and pulmonary trunk; one (Case P077) had pulmonary stenosis and transposition of the aorta and pulmonary trunk; and the third (Case H142) had a large atrial septal defect, a single ventricle, and pulmonary valvular stenosis (Campbell, Reynolds, and Trounce, 1953). The last was the only patient of this group in whom a subclavian-pulmonary anastomosis was attempted.

Twelve of these 15 had an upright PI so that generally the picture differs from that of dextrocardia with transposed abdominal viscera (Table I). Only. 3 of the 15 had PI inversion; possibly the three exceptions had mirror-image dextrocardia without transposed abdominal viscera which is unusual.

TABLE I

The P Wave in Patients with Heart and/or Viscera Transposed

\begin{tabular}{l|c|c|c|c}
\hline & $\begin{array}{c}\text { PI and PII } \\
\text { upright }\end{array}$ & $\begin{array}{c}\text { PI } \\
\text { inverted }\end{array}$ & $\begin{array}{c}\text { PII and PIII } \\
\text { inverted }\end{array}$ & Total \\
\cline { 2 - 5 } Situs inversus totalis & 2 & 91,2 & 0 & 11 \\
Isolated dextrocardia & $123,4,5$ & 36 & 0 & 15 \\
Isolated lævocardia & 4 & 67 & 4 & 14 \\
\hline
\end{tabular}

1. PI was generally inverted with a $\mathbf{P}-\mathbf{R}$ interval of $0 \cdot 17$ but sometimes upright with a $P-R$ interval of $0 \cdot 12$ sec. in Case 0646.

2. PI was sometimes inverted but sometimes upright with PII and PIII inverted in Case O392.

3. PI was almost flat in Case 0784 .

4. PI was sometimes upright but sometimes inverted with inversion of PII and PIII as well, without any change in the P-R interval in Case O237.

5. PI was triphasic, at first upright, then downwards and then again upright in Case P165.

6. PII and PIII were also inverted in Case 0854.

7. PI was biphasic, though the inversion came first and was deeper, in Case P105; and PI was generally inverted but sometimes upright with PII and PIII inverted, and often with shorter P-R interval in Case O556.

Isolated Lavocardia. Although fewer cases have been reported, this seems to be about as common as isolated dextrocardia. In our series there were 14 cases with the heart on the left but with the abdominal viscera completely or mainly transposed. All had other congenital malformations of the heart, 12 being cyanotic and 2 acyanotic, almost exactly the same figures as for isolated dextrocardia.

Four have died but one had no necropsy. One (Case O136) had a bilocular heart and has been fully reported (Campbell, Gardner, and Reynolds, 1952): one (Case P130) had mitral atresia, a single ventricle, and severe pulmonary valvular stenosis (Campbell, Reynolds, and Trounce, 1953): and one (Case O405) had a ventricular septal defect, partial transposition of the aorta and pulmonary trunk, and infundibular and pulmonary valvular stenosis. In Case P130 transposition of the abdominal viscera was not quite complete.

In this group with isolated lævocardia, the direction of the $P$ wave is less consistent than in those with either type of dextrocardia, i.e. with the abdominal viscera transposed or in their normal position. It was inverted in 6 of the 14, but upright in the other 8, though PII and PIII were inverted in 4 of these 8 (Table I and Fig 1). The anatomical significance of an upright PI with inversion of PII and PIII is not yet known, but we put forward the following hypothesis. Where the abdominal viscera are transposed, the sinu-atrial node might be expected to develop in the primitive atrium on the side opposite to the normal, i.e. below the left horn of the sinus venosus. One might now expect a superior vena cava and venous atrium to be formed on the left. If, however, the further development is reversed and results in a superior vena cava and venous atrium on the right, the sinu-atrial node, by remaining in relation to the left horn of the sinus venosus, comes to lie adjacent to the coronary sinus. Hence, the pacemaker lies in the lower part of the 
right atrium with consequent inversion of PII and III. If this hypothesis is correct it may mean that the right-sided venous atrium in these cases is embryologically a left one though at an early stage its development is reversed.*

The relevant anatomy is known in one only (Case 0136) and here bilateral superior venæ cavæ were present and entered a common atrium, the right directly but the left through the coronary sinus: this suggests that the venous half of the atrium was in its normal position.

Similarly, in cases with inversion of the $P$ waves in all the standard leads the sinu-atrial node may be lying in relation to the coronary sinus entering a left-sided venous atrium.

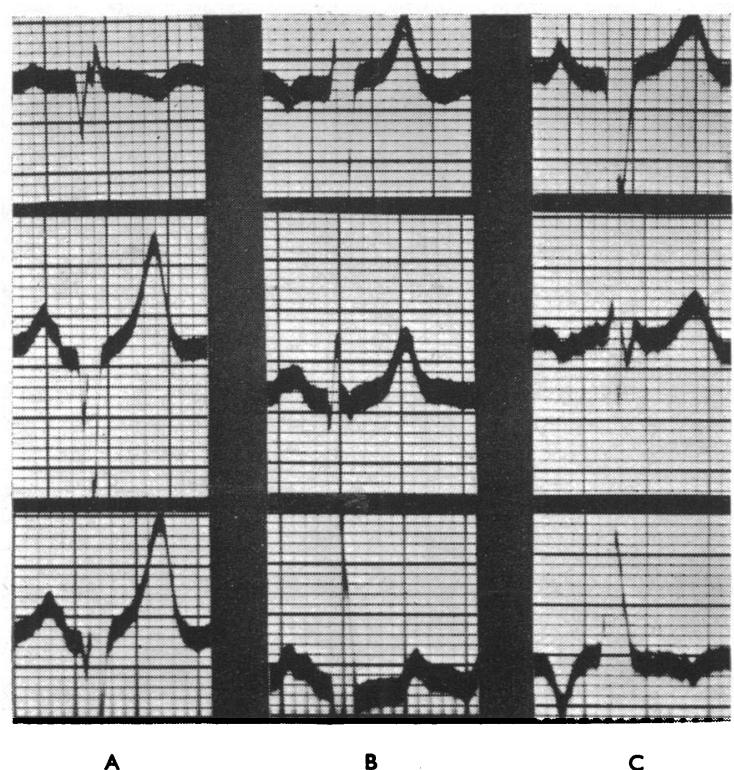

Fig. 1.-(A) The usual electrocardiogram from isolated dextrocardia, showing an upright $\mathbf{P}$ wave and a $\mathbf{Q}$ wave in lead I. (B) The common form of the electrocardiogram from isolated lævocardia showing an inverted $P$ wave but no $Q$ wave in lead I. (C) The less common form of the electrocardiogram of isolated lævocardia showing an inverted $\mathbf{P}$ wave in leads II and III.

\section{The Relationship of the Direction of the P Wave to the Side of the Superior Vena Cava and the Venous Atrium}

The direction of the $\mathrm{P}$ wave is, therefore, related to the position of the abdominal viscera more closely than to the position of the heart, though not constantly to either. There is, however, a constant relationship between the direction of PI and the side of the venous atrium in these cases, as shown by the superior vena cava, as far as this is known at present. In all 9 with this vessel in its normal position on the right, regardless of the side of the heart itself, PI was upright; while in all 7 with this vessel on the left, PI was inverted.

Bilateral superior venæ cavæ were present in 5 other cases; in 3 the side of the venous atrium was known and was on the right, and PI was upright in all three, PII and III being inverted in one of them (Table II).

Apart from these cases of dextrocardia and lævocardia, we have seen many examples of a persistent left superior vena cava, with both superior venæ cavæ present. In all of these the left superior vena cava reaches the right atrium through the coronary sinus, so that there is no change in the position of the venous atrium or in the pattern of the electrocardiogram.

*We have recently examined the only available heart (Case O136) and have failed to find any direct support for this hypothesis, but the heart had been preserved for two years before any sections were taken. 
TABLE II

The Relationship of Upright and INVERTed P WaVes to the Position of the SuPERIOR Vena CAVA AND OF tHe AORTA

\begin{tabular}{l|c|c|c|c}
\hline & $\begin{array}{c}\text { PI and II } \\
\text { upright }\end{array}$ & $\begin{array}{c}\text { PI } \\
\text { inverted }\end{array}$ & $\begin{array}{c}\text { PII and III } \\
\text { inverted }\end{array}$ & Total \\
\cline { 2 - 4 } S.V.C. on right & 94 & 0 & 0 & 9 \\
S.V.C. on left & 0 & 72,7 & 0 & 7 \\
S.V.C. on R. and L. & $2^{*}$ & 2 & $1^{*}$ & 5 \\
Left-sided aorta & 11 & 46 & 2 & 17 \\
Right-sided aorta & 6 & $131,2,7$ & 2 & 21 \\
\hline
\end{tabular}

* These all had the venous atrium on the right. For othẹr footnotes see Table I.

This close relationship between the direction of PI and the side of the superior vena cava is not surprising since the $\mathbf{P}$ wave originates in the sinu-atrial node which lies close to the opening of the superior vena cava into the venous atrium. It is perhaps not widely recognized that the superior vena cava, venous atrium, and aortic arch are usually not transposed in an isolated dextrocardia, but are frequently transposed in an isolated lævocardia (Table III). It appears that the direction of PI will indicate whether this is so or not in any particular case.

TABLE III

The Side of the Superior Vena Cava and of the Aorta in Patients with the HEART AND/OR VISCERA TRANSPOSED

\begin{tabular}{|c|c|c|c|c|c|c|c|c|c|}
\hline \multirow[b]{2}{*}{$\begin{array}{l}\text { Situs inversus totalis.. } \\
\text { Isolated dextrocardia } \\
\text { Isolated lævocardia .. }\end{array}$} & \multirow[b]{2}{*}{$\begin{array}{l}. \\
\therefore\end{array}$} & \multicolumn{4}{|c|}{ Side of S.V.C. } & \multicolumn{3}{|c|}{ Side of Aorta } & \multirow{2}{*}{$\begin{array}{l}\text { Total } \\
\\
11 \\
15 \\
14\end{array}$} \\
\hline & & $\begin{array}{c}\mathrm{R} . \\
2 \\
6 \\
1\end{array}$ & $\begin{array}{l}\mathrm{L} . \\
2 \\
1 \\
4\end{array}$ & \begin{tabular}{|c} 
R. \& L. \\
2 \\
1 \\
2
\end{tabular} & $\begin{array}{c}\text { Not } \\
\text { known } \\
5 \\
7 \\
7\end{array}$ & $\begin{array}{r}\text { L. } \\
2 \\
11 \\
4\end{array}$ & $\begin{array}{r}\mathbf{R} . \\
9 \\
2 \\
10\end{array}$ & $\begin{array}{c}\text { Not } \\
\text { known } \\
0 \\
2 \\
0\end{array}$ & \\
\hline Total & . & 9 & 7 & 5 & 19 & 17 & 21 & 2 & 40 \\
\hline
\end{tabular}

The Side of the Aortic Arch

Since the superior vena cava and the arch of the aorta are usually on opposite sides there is also some relationship, though a less close one, between the direction of PI and the side of the aortic arch. As it is easier to find the side of the aortic arch than of the superior vena cava or the venous atrium, this is worth considering.

In 13 of the 17 cases with a left-sided aortic arch PI was upright, while in 13 of the 21 cases with a right-sided aortic arch PI was inverted (Table II). In the 4 cases where the arch of the aorta and the superior vena cava with the venous atrium were known to be on the same side, PI had the form to be expected from the side of the superior vena cava.

Taussig (1947) says that in cases of dextrocardia (presumably with situs inversus) it is important to remember that a right-sided aortic arch is normal, but that a left-sided aortic arch is relatively common in cases of dextrocardia combined with persistent cyanosis and that this is true whether there is complete situs inversus or not. The last part of the remark is only true because in most of the cyanotic cases with dextrocardia and situs inversus there is not true mirror-image dextrocardia. Brown (1950) says that in isolated dextrocardia the aortic arch is more often left- than right-sided when the cavities are inverted and usually left-sided when they are not.

We do not think there is any constant relationship, but a left-sided aortic arch is more common with isolated dextrocardia and a right-sided arch with isolated lævocardia (Table III). 


\section{DisCUSSION}

The four basic anatomical patterns that are most usual are shown in Fig. 2, which indicates diagrammatically the position of the ventricle, the venous atrium, the superior vena cava, the aortic arch, and the stomach as representing the abdominal viscera. Most commonly the aortic arch and the superior vena cava follow the abdominal viscera, though there are exceptions where one or other or both follow the heart rather than the other viscera.
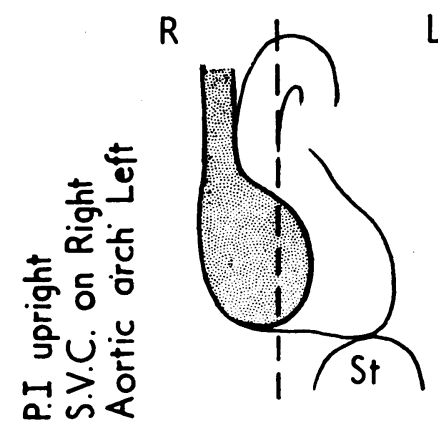

NORMAL

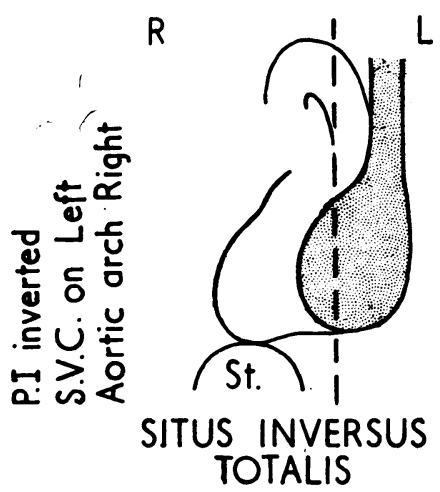

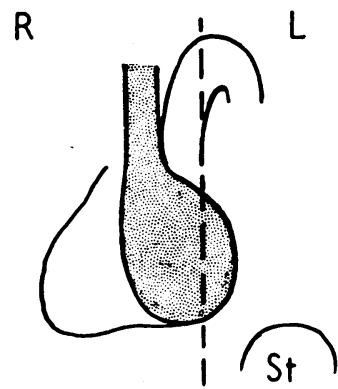

ISOLATED DEXTROCARDIA

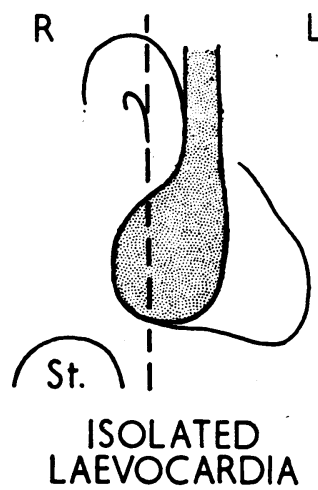

FIG. 2.-Diagram of the four most common relationships of the heart and vessels to demonstrate the position of the superior vena cava, of the venous atrium, of the ventricles, and of the aortic arch. St.=stomach. The pattern shown for isolated lævocardia is the least constant of these.

The venous atrium always appears to follow the superior vena cava and for this reason the direction of the $P$ wave in lead $I$ will show whether they are in their normal position or transposed. The ventricles are not always transposed when the atria are: being the main part of the heart they must generally lie as the heart appears to.

This is supported by the electrocardiographic pattern of QRS. The QRS complex of lead I of a mirror-image dextrocardia normally shows a $Q$ wave, which may not, however, be predominant when the venous ventricle is hypotrophied. Among our 11 cases of dextrocardia with complete situs inversus this was so in every case. A QI was also present in 10 of the 15 cases of isolated dextrocardia, including 7 of the 12 where PI was upright; this suggests, as does their anatomical position, that in these at least the ventricles were transposed while the atria were not. On the 
other hand a QI was present in only 4 of the 14 cases of isolated lævocardia, including only 2 of the 6 where PI was inverted, which suggests that in the others normally placed ventricles were associated with transposed atria. In those cases where the form of the QRS complex does not tally with the anatomical position of the ventricle, it may be that the ventricles are rotated rather than transposed.

The main exceptions to the patterns shown in Fig. 2 are found in the group with isolated lævocardia. Here only about half the $\mathrm{P}$ waves point in the direction that might be expected. Presumably in the other half the venous atrium (and perhaps the superior vena cava) has not been transposed but has remained in its normal position as the rest of the heart has.

Forgacs (1947), developing the suggestion of Lochte (1898), thought that there was transposition of the atria in most of these cases. Possibly, when there is an upright PI in isolated lævocardia the venous atrium has not been transposed, i.e. has followed the ventricles and not the abdominal viscera. On the other hand, the cases with an inverted PI are those that have followed the pattern shown in our Fig. 4 and here the atrium is anatomically transposed, as suggested by Forgacs (1947). It will be interesting to see when more cases have been fully investigated by angiocardiography or post mortem, if anatomical support for this view can be obtained.

Since writing this we have seen a recent book by Soulié (1952). In the cases of situs inversus with dextrocardia he, of course, expresses the orthodox view, but adds:

“ 'Ce signe (une onde PI négative) n'est pas absolument pathognomonique: il a été observé dans quelques cas de cardiopathies congenitales sans situs inversus."

In isolated dextrocardia without transposition of the viscera, he states: "l'onde PI demeure toujours positive," and with this we are in agreement in so far as it includes all those cases where the superior vena cava also is not transposed. Finally, in lævocardia without transposition of the abdominal viscera he says: "L'electrocardiogramme peut montrer, comme dans le situs inversus avec dextrocardie, une onde PI négative."

Doliopoulos and Maillet (1952) have reported 5 cases of their own of isolated lævocardia and discuss 34 reported cases. Although according to them negativity of PI was considered to be pathognomonic of inversion of the auricles, they concluded that this view was not really supported by the cases reported, without presenting any convincing evidence for this conclusion. Electrocardiograms were available in only a proportion of the cases they considered. In 16 where the diagnosis was not proved by necropsy the $P$ wave in lead $I$ was inverted in 4 , and in 4 cases where the diagnosis was supported by necropsy PI was inverted in one and isoelectric in one.

\section{CONCLUSIONS}

Cyanotic congenital heart disease is not uncommon in dextrocardia with situs inversus. Here the $\mathbf{P}$ wave in lead $\mathbf{I}$ is generally inverted, as in normal situs inversus totalis.

Cyanotic heart disease is almost universal in isolated dextrocardia without transposition of the abdominal viscera and in isolated lævocardia with transposition of the viscera.

In isolated dextrocardia the $\mathbf{P}$ wave in lead I is most often upright. It is always upright in those cases where the venous atrium and the superior vena cava have remained in their normal position.

In isolated lævocardia the $P$ wave in lead $I$ is often inverted. It is always inverted in those cases where the venous atrium and the superior vena cava have been transposed with the abdominal viscera. However, this pattern is found less constantly in isolated lævocardia than the opposite pattern in isolated dextrocardia.

An upright PI with inversion of PII and PIII is another common pattern in isolated lævocardia. This may be because the sinu-atrial node lies low in the atrium, adjacent to the coronary sinus.

The side of the aortic arch will give some clue to the probable anatomical arrangements but less constantly than the side of the superior vena cava does. 


\section{REFERENCES}

Beaujeu, A. J. de, and Bège, R. (1937). Arch. Mal. Caur, 30, 977.

Brown, J. W. (1950). Congenital Heart Disease. 2nd ed., Staple Press, London.

Campbell, M., Gardner, F., and Reynolds, G. (1952). Brit. Heart J., 14, 317.

Campbell, M., Reynolds, G., and Trounce, J. R. (1953). Guy's Hosp. Rep. (in the press).

Doliopoulos, T., and Maillet, J. (1952). Cardiologia, 20, 80.

Donzelot, E., Emam-Zade, A., de Balsac, R. H., and Metianu, C. (1949-50). $\quad$ Acta med. scand., $136,13$.

Forgacs, P. (1947). Brit. Heart J., 9, 27.

Grieshaber, H. (1936). Schweiz. med. Wschr., 66, 1307.

Lichtman, S. S. (1931). Arch. intern. Med., 48, 683.

Lochte, - (1898). Beitrag. path. Anat. allg. Path., 24, 187.

Röesler, H. (1930). Wien. Arch. inn. Med., 19, 505.

Ruskin, A., Tarnower, H., Lattin, B., and Robb, G. P. (1943). Amer. Heart J., 25, 116.

Shaw, E., and Blake, H. K. (1924). Amer. J. Dis. Child., 28, 204.

Soulié, P. (1952). Cardiopathies Congénitales. L'Expansion Scientifique Française, Paris.

Taussig, H. (1947). Congenital Malformation of the Heart. Commonwealth Fund, New York.

Thomson, J. (1950). Brit. Heart J., $12,147$.

White, P. D. (1951). Heart Disease. 4th ed., The Macmillan Co., New York

Wood, P. (1950). Diseases of the Heart and Circulation. Eyre and Spottiswoode, London.

Young, M. D., and Griswold, H. E. (1951). Circulation, 3, 202. 